Health Policy Insight, London, UK Cite this as: $B M / 2022 ; 376: 015$ http://dx.doi.org/10.1136/bmj.015 Published: 06 January 2022

\title{
Omicron: Who needs action when you've got Plan B?
}

\section{Andy Cowper editor}

NHS staff would be excused a feeling of déjà vu, as 2022 kicks off with hospitals being what Boris Johnson, the UK prime minister, is absolutely, definitively, really, really sure is not "overwhelmed."

Many might not agree given the number of NHS trusts declaring a critical incident, but the prime minister has a cunning plan to prevent the NHS being "overwhelmed." The plan? You simply never define what an "overwhelmed" NHS is, and then it simply can't happen. Clever, eh?

Unfortunately for Johnson, reality has a chronic habit of intruding on his boosterish, feel good approach to the pandemic, and is in the process of doing exactly this once again.

As Johnson told the media at the start of this week at a Downing Street press briefing, "I think we've got to recognise that the pressure on our NHS, on our hospitals, is going to be considerable in the course of the next couple of weeks, and maybe more. No matter how incredibly transmissible omicron is...it is different from previous variants. It does seem pretty conclusively to be less severe than delta or alpha, and it is putting fewer people into ICU.”

This is currently true: fewer patients are being put into mechanical ventilation beds compared with January 2021, but omicron is still putting a lot more people into hospital than we've seen since last winter. ${ }^{1}$ The latest data saw a $50 \%$ rise in acute admissions between 20 December and 28 December. ${ }^{1}$ And this extra pressure on an NHS that is already crammed with now urgent cases from the growing NHS backlog is creating some quite predictable chaos.

\section{Critical incidents and stopped routine care}

Plymouth Derriford, Blackpool, and Morecambe Bay NHS Trusts have followed United Lincolnshire Hospitals NHS Trust into declaring critical incidents (the highest state of alert) over staff absences. They have now been joined by University Hospitals Dorset. ${ }^{2}$

Almost the entire Greater Manchester region's hospitals paused non-urgent surgery and appointments, although they have not yet declared critical incidents. ${ }^{3}$ This follows $15 \%$ of the region's hospital staff becoming sick with covid-19 or having to self-isolate (the usual staff absence figure over winter is $5 \%$ ).

\section{Prime minister's Downing Street briefing}

On Monday 5 January, a grateful nation was treated to its first covid-19 Downing Street briefing of 2022. It was as remarkable as many of the others have been.

For example, Johnson's opening assertion that “we have higher vaccination than our European neighbours" line is not really true, as the evidence shows. ${ }^{4}$

\section{Less test and trace, more "trace a test"}

"You've got to make sure you get a test," the prime minister advised the nation, apparently unaware that tests have been and remain in massively short supply..$^{5}$ Indeed, Sajid Javid, the health secretary, talked about having to "constrain" the system of supply over the coming fortnight, which includes the return of schools.

\section{Flogging a dead-tired workforce}

"We're increasing the number of staff," the prime minister also promised. Longer term, there is more recruitment and training, although of the relevant staff who are trained and working right now, many are currently off work sick or isolating due to covid-19, as the Sunday Times revealed this weekend. ${ }^{6}$

The prime minister also said, "I just think we have to get through it as best as we possibly can. We'll give the NHS all the support we can.”

\section{Aren't you reassured?}

When is a tent in a hospital car park not a tent in a hospital car park? When it's a mini-Nightingale

As an example of this support, the prime minister also praised the new "mini-Nightingales," while oddly failing to mention that these are tents in hospital car parks-with no new staff.

Yet none of what's happening can be deemed a surprise. It is the result of the simple mathematics of exponential growth. While so far it looks like omicron causes less critical illness, it still causes illness and some hospital admissions. Omicron's higher infectiousness inevitably means that the small percentage of a very large number of infected people is still a big number and a big problem for the NHS and its staff.

The mathematics of this exponential growth have hit the workforce hard. Likewise the general population. As the Financial Times's chief data reporter John Burn-Murdoch pointed out in an excellent Twitter thread, the data indicate clearly how the real demand problem will arise as omicron makes its way into the older and most vulnerable 65 +patient population. ${ }^{7}$

Elsewhere, the UK Health Security Agency has just announced that confirmatory PCR tests will not be used after 11 January when a lateral flow test is found to be positive.

At the same time, the Office For National Statistics released data from its national Infection Survey, showing that 1 in 15 people in England had covid-19 in the week to 31 December 2021, and 1 in 10 in London. ${ }^{8}$

All of which suggests, this is going to be another very tough January. 


\section{OPINION}

Competing interests: none declared

Provenance and peer review: commissioned, not peer reviewed

1 GOV. UK Coronavirus in the UK. Healthcare in the United Kingdom. https://coronavirus.data.gov.uk/details/healthcare?areaType=overview\%26areaName=United\%20Kingdom\#card-patients_in_mechanicaL_ventilation_beds

2 lacobucci G. Covid-19: NHS trusts declare "critical incidents" because of staff shortages. BMJ 2022;376:03. doi: 10.1136/bmj.03.

3 Twitter. Jennifer Williams. https://twitter.com/jenwilliamsmen/status/1478466787654213637

4 Statista. Number of COVID-19 vaccine doses administered in Europe as of December 14, 2021, by country. https://www.statista.com/statistics/1196071/covid-19-vaccination-rate-in-europe-bycountry/

5 lacobucci G. Covid-19: GP practices can access "contingency supply" of lateral flow and PCR tests. BMJ 2022;376:04. doi: 10.1136/bmj.04.

6 The Sunday Times. NHS struggles as sickness takes out 1 in 10 staff. https://www.thetimes.co.uk/article/nhs-struggles-as-sickness-takes-out-1-in-10-staff-x29mwv5rw

$7 \quad$ Twitter, John Burns-Murdoch. https://twitter.com/iburnmurdoch/status/1478339769646166019

8 Office for National Statistics. Coronavirus (COVID-19) Infection Survey headline results, UK: 5 January 2022. https://www.ons.gov.uk/peoplepopulationandcommunity/healthandsocialcare/conditionsanddiseases/bulletins/coronaviruscovid19infectionsurveypilot/5january2022 